\title{
Carl Friedrich Gauss and the Gauss Society: a brief overview
}

\author{
Axel D. Wittmann ${ }^{1, \text { 出 }}$ \\ ${ }^{1}$ Institut für Astrophysik, University of Göttingen, 37124 Rosdorf, Germany \\ $i_{\text {retired }}$ \\ Correspondence: Axel D. Wittmann (wittmann.rosdorf@t-online.de)
}

Received: 20 May 2020 - Revised: 24 July 2020 - Accepted: 1 August 2020 - Published: 8 September 2020

\begin{abstract}
Carl Friedrich Gauss (1777-1855) was one of the most eminent scientists of all time. He was born in Brunswick, studied in Göttingen, passed his doctoral examination in Helmstedt, and from 1807 until his death, was the director of the Göttingen Astronomical Observatory. As a professor of astronomy, he worked in the fields of astronomy, mathematics, geodesy, and physics, where he made world-famous and lasting contributions. In his honour, and to preserve his memory, the Gauss Society was founded in Göttingen in 1962. The present paper aims to give nonspecialists a brief introduction into the life of Gauss and an introduction into the Gauss Society and its history.
\end{abstract}

\section{Carl Friedrich Gauss - an unusual career in science}

Carl Friedrich Gauss was one of the most eminent scientists ever, and, like, for example, Archimedes (288-212 BCE) or Sir Isaac Newton (1642-1727), whom he admired most, was competent and singularly made everlasting contributions in more than one field, namely mathematics, astronomy, geodesy, and physics. He was an outstanding genius in mathematics, but his main profession (from which he earned his income) was that of an astronomer. At the age of 30 years, he became a professor of astronomy and the director of the Göttingen Observatory. Another world-famous astronomer, Nicolaus Copernicus (1473-1543), once wrote about this field, as follows: “... while it is a property of all sciences to distract from leading a depraved life, astronomy can do this to an especially high degree, apart from the incredibly high degree of satisfaction which it provides" (Hermanowski, 1996). A similar statement was made by Gauss in 1804: "According to my feelings, practical astronomy right next to the joy of heart and the inspection of truth in pure mathematics - is the sweetest pleasure which we can have on Earth" (letter to Farkas Bolyai, 25 November 1804). This shows that, as a post-doctoral fellow, Gauss was already interested in astronomy. At that time he was in love with a local woman, looking for a job, and already world- famous because in 1801 he had rediscovered the missing planet of Ceres Ferdinandea. Gauss was born in Brunswick on 30 April 1777. At the age of about 3 years, Gauss's talents in mathematics became evident, and a bit later, in elementary school, he himself discovered a fast algorithm for finding the sum of an arithmetic series. He was 9 years old at the time. Subsequently, Gauss was sponsored by Carl Wilhelm Ferdinand, the Duke of Brunswick, and after completing high school, he received a stipend which enabled him to study "abroad", at the university in Göttingen, which was famous for its collection of mathematical literature. This was quite unusual because, at that time, Brunswick had a state university of its own in nearby Helmstedt. When he was a student in Göttingen in 1796 (and on a short visit to his parents in Brunswick), Gauss made his first important discovery in mathematics. He found rigorous evidence for the constructibility of the heptadecagon or the 17-gon. This proof or disproof - had been sought since the time of Euclid, i.e. for more than 2000 years. Even a mathematical genius like Johannes Kepler had considered the heptadecagon as being impossible to construct. This discovery became the first entry in Gauss's famous "mathematical diary", in which he briefly noted most of his discoveries until 1813. It was typical of Gauss not to publish everything without careful consideration. But his first-ever publication - a note on his discovery 
concerning the heptadecagon - was so lacking in detail about how his result was derived, gave no earlier references, and it did not actually present his proof that it would have been immediately rejected by a modern editor. Actually, Gauss's papers, due to his laxness in his citation of other publications (he tacitly assumed that everyone would know them anyway), would have been rejected by most of today's peerreview systems. As a student of classical literature and classical languages (in which he was fluent) in Göttingen, Gauss became more and more interested in astronomy and made his first observations of the night sky using a professional telescope (a mural quadrant by John Bird) at the former (the "old") Göttingen Astronomical Observatory. This was very famous due to the work of Tobias Mayer (1723-1762), whom Gauss always admired greatly. In September 1798 Gauss returned to Brunswick and started his doctoral degree, which he received from the Duke of Brunswick's own university in Helmstedt. In his thesis, Gauss delivered the first rigorous argument for the "fundamental theorem of algebra". In August 1800 , Gauss published a numerical algorithm for calculating the date of Easter. This was his first astronomical publication, and his algorithm is still in use today. In 1801 he published his main mathematical monograph, the Disquisitiones arithmeticae. Together with Newton's Philosophice Naturalis Principia Mathematica, this work is considered to be one of the great masterpieces of science. Shortly afterwards, an event occurred which made Gauss turn to astronomy forever and which made him world-famous overnight. It had been known for a while that there was a gap in the planetary distances between Mars and Jupiter. As Lichtenberg had stated in his lecture: "According to the gap in the arithmetical progression, one has to place an imaginary planet between Mars and Jupiter" (Gamauf, 1814).

This planet was desperately searched for by many people since it provided a unique opportunity to become famous without an academic education (or even any education at all). On 1 January 1801, the Italian astronomer Giuseppe Piazzi observed a small, star-like object of an eighth magnitude which, on the following nights, moved among the stars in the same way that a planet or a comet would. But he could not continue his observation, and the planet was lost. The most famous astronomers of the time tried to calculate an orbit in order to recover the "lost planet", but they were wrong by about 10 to $15^{\circ}$, and it was not until Gauss published his calculations that Ceres - as the planet was finally named - was rediscovered in December 1801 by Franz Xaver von Zach.

In 1805, Gauss married a charming young lady from Brunswick, Johanna Osthoff. She was the great love of his life but, unfortunately, died 4 years later. In 1807 - shortly before Göttingen came under the rule of Jerôme Bonaparte - Gauss was appointed as a professor of astronomy and the director of the Göttingen University Observatory by the Hanoverian government. The observatory was under still construction, slightly to the southeast of Göttingen and just outside the town wall, and was finished in 1816. Following

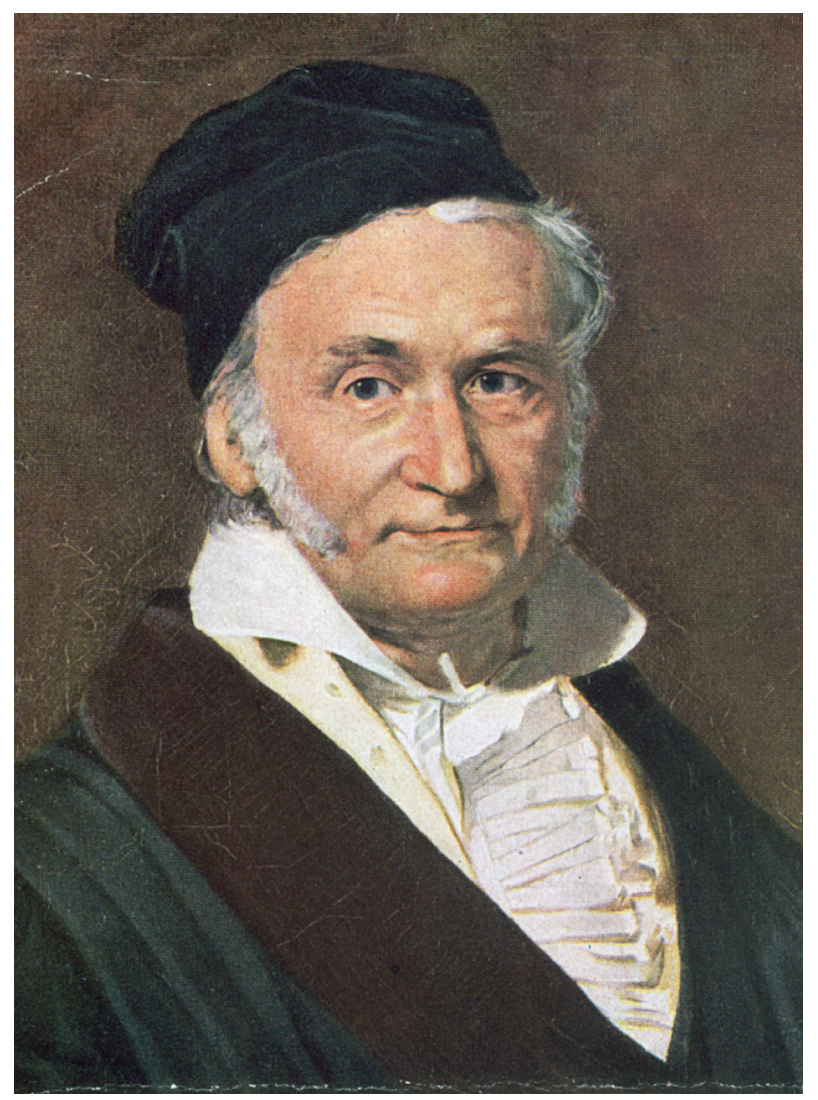

Figure 1. Carl Friedrich Gauss, painted by Gottlieb Biermann (1887). Reproduction by the author from a calendar dated June 1939; this is the first known colour print of a portrait of Gauss.

the terrible shock after the loss of his beloved Johanna, Gauss mourned intensively and then married again, this time to Wilhelmine Waldeck, a close friend of his deceased wife, and they had three more children. At approximately this time, Gauss wrote a paper titled Theoria Interpolationis Methodo Nova Tractata, in which, among other things, he developed the theory of the fast Fourier transform (FFT), which was in almost the same form as it is used today. Space constraints do not permit the mention of Gauss's many other contributions to pure and applied mathematics which made him one of the most outstanding mathematicians of all time. In 1809, Gauss published his most important monograph in astronomy, the Theoria Motus Corporum Coelestium, which also contained an account of his method of least squares and the Gaussian distribution curve. If the Nobel Prize had existed in 1809, Gauss might have received it. Of all the academic lectures Gauss held in Göttingen, $70 \%$ dealt with astronomy, $15 \%$ with mathematics, $9 \%$ with geodesy, and $6 \%$ with physics; one would not expect such statistics from a professor of mathematics. Notwithstanding his mathematical talents, Gauss earned his income as an astronomer. Although he did not like lecturing very much, Gauss educated a school of successful astronomers (among them Schu- 
macher, Encke, Nikolai, Möbius, Gould, and Klinkerfues) and a slightly lesser number of successful mathematicians (among them Riemann, Dedekind, Cantor, von Staudt, and Schering). With some of his pupils Gauss maintained lifelong friendships, and his closest friends were Olbers, Schumacher, Gerling, and Encke.

Competent scientists should change their research interests every 10 years during their lives (this is "Fermi's recommendation"), and Gauss did that. From 1821 until 1824 he conducted and actively participated in the project of land surveying ("triangulation") in northern Germany, which extended westwards into what is today the Netherlands and eastwards to the former capital of Prussia, the town of Berlin. On this occasion, he invented the heliotrope, a device used to direct sunlight, with arcsecond accuracy, in any given direction. This was a forerunner of modern laser devices. And he developed the Gauss-Krüger coordinate system for conformably mapping the surface of the Earth. Since its rediscovery by the US Army in 1947, this system has also become known as the Universal Transverse Mercator (UTM) coordinates and is in global use as GPS coordinates (which are mathematically the same). In Göttingen, Gauss also made important contributions to physics, optics, crystallography, Earth magnetism, insurance mathematics, etc. Gauss and Weber - slightly influenced by Humboldt - initiated what may be called the first international geophysical year by establishing a network of 53 Earth magnetic stations around the world. The results were collected and analysed in Göttingen. And, in April 1833, Gauss and Weber invented the first fully operational electromagnetic telegraph in the world. This was the beginning of today's worldwide communication by telegraph, telefax, and SMS through mobile phones. As a result of his talents and his reputation, Gauss was elected as a member of scientific academies in Germany, Russia, England, Spain, and France, and he received approximately 75 foreign awards, medals, and decorations. But Gauss disliked travelling and never travelled very far. Most of the awards were papers sent to him, and just a few were objects (a pendulum clock from Paris, the Copley medal from London, etc.) which were brought to Göttingen by colleagues or students. Gauss's last scientific achievement was a short, but very sensitive, Foucault-type pendulum, which he invented in 1854. Today, we rank Gauss among the titans of science, like Archimedes and Sir Isaac Newton. His contributions to non-Euclidean geometry and the curvature of space were explicitly acknowledged by Einstein on several occasions. Gauss died peacefully of heart and lung failure on 23 February 1855 at the age of almost 78. A journal in Brunswick wrote, "He ended his life in order to transit into those worlds which he had so diligently observed for a long time" (Braunschweigisches Magazin, 18 July 1857). Gauss has been honoured posthumously by paintings, busts, statues, medals, coins, postage stamps, banknotes, etc., which are too numerous to be described here.

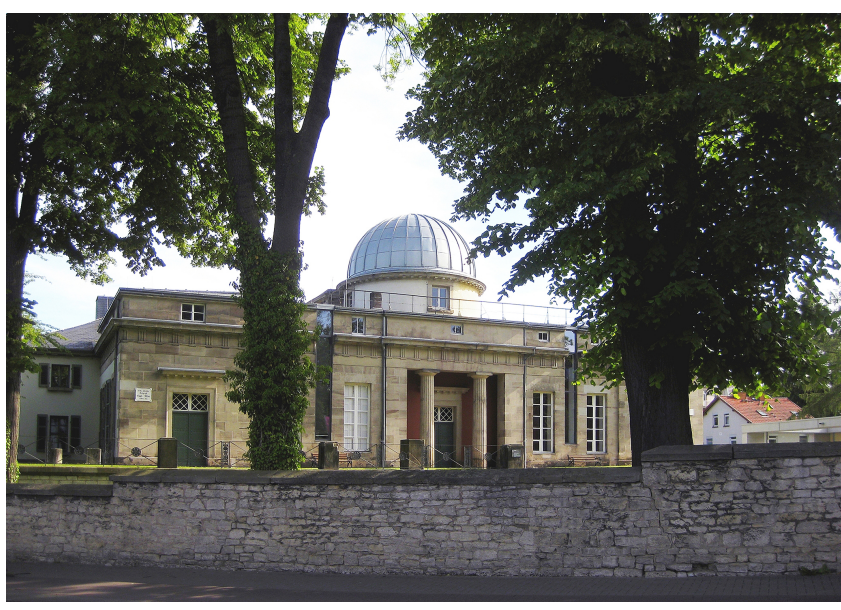

Figure 2. Gauss's former observatory, the "Sternwarte Göttingen" (photograph by the author).

\section{The Gauss Society (Gauss-Gesellschaft e.V.) and its history}

Gauss was a well-reputed, honourable, and decent character devoted to science, his family, and to his students, colleagues, and friends. In the late 1950s, there emerged a necessity among some of the local admirers of Gauss to preserve his memory and his achievements. On 17 May 1962 the registered association called the "Gauss-Gesellschaft" (Gauss Society) was founded by a group of 14 persons in Göttingen, among them the mayor of Göttingen, some famous scientists, and - last but not least - Horst Michling (1909-2003), who was the head of the geodesy department of the Göttingen town administration. Michling is considered to be the founder of the Gauss Society. The aims of the society were put in writing in the statutes. Among others, they were to preserve the memory of Gauss, to organise publications and lectures, and, by remaining in close contact with the University of Göttingen and the Göttingen Academy of Sciences, to conduct and publish research on the life and works of Gauss. During the following years, several members of the Gauss Society contributed important research and completely new findings on Gauss and his many unpublished works. Starting in 1964, the Gauss Society has issued an annual publication (a sort of yearbook) called "Mitteilungen der Gauss-Gesellschaft" (ISSN 04351452), of which 57 volumes have been published (until 2020; for details, see http://www.gauss-gesellschaft.de, last access: 5 September 2020). This publication is a mayor source of research about the works of Gauss and more recent developments in astronomy, mathematics, physics, and geodesy related to Gauss. Medals dedicated to Gauss were issued in 1856, 1877, 1933, and 2005. The first president of the Gauss Society was the famous geophysicist Julius Bartels (Fig. 3), who, unfortunately, died in March 1964. 


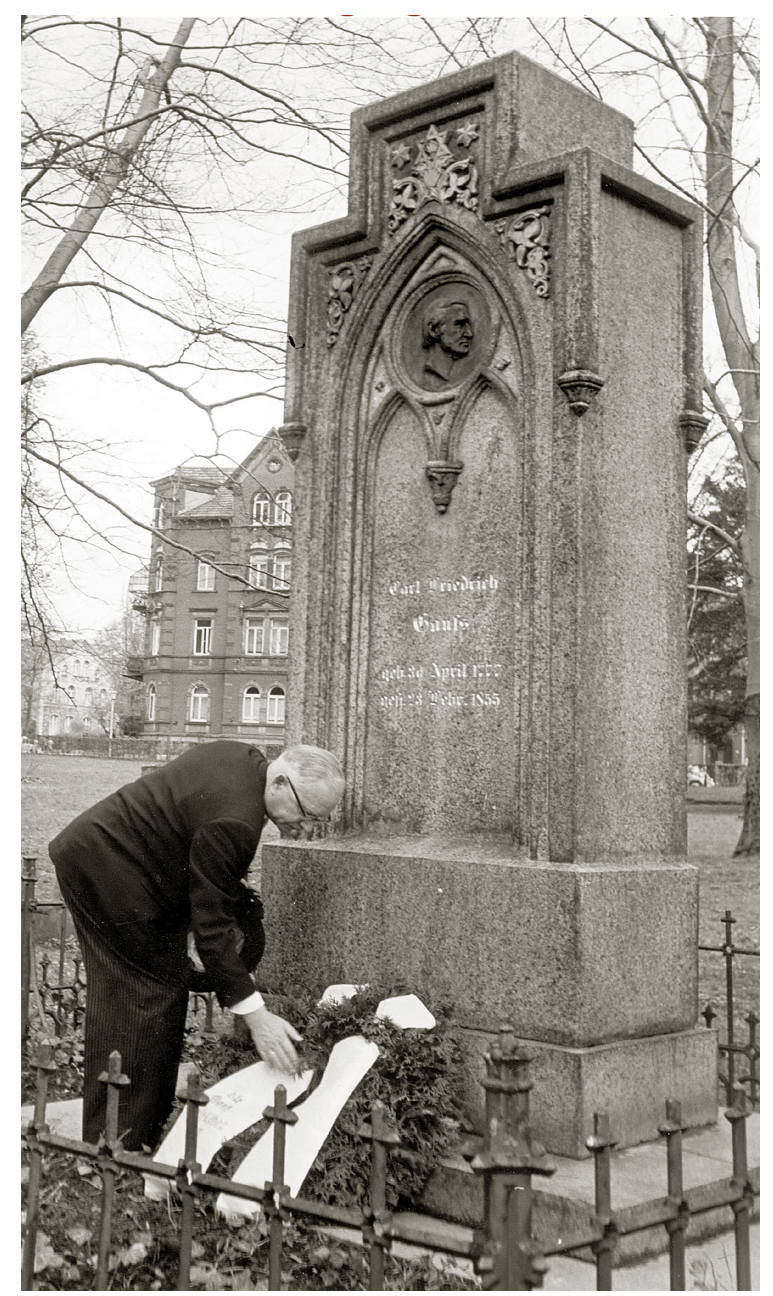

Figure 3. The geophysicist Julius Bartels, the first president of the Gauss Society, laying a wreath at the grave of Gauss in 1963 (photograph from the Gauss Society archives).

In 1977 important celebrations were organised both in Brunswick and in Göttingen in order to commemorate Gauss's 200th birthday. In 1982 the Gauss Society celebrated its 40th anniversary in the ancient town hall of Göttingen. Then, in the year 2005 (which was officially called the "Gauss Year") many celebrations, a series of public lectures organised by the Göttingen Academy of Sciences, and an exhibition in the ancient town hall of Göttingen were organised, and Gauss medals were issued in both silver and gold. Many new books and articles (both scientific and fiction) about Gauss and his life appeared in that year (Fig. 4)

Since 1962 the Gauss Society has organised 58 annual meetings and approximately 43 excursions, and it has instigated and largely designed monuments at some of the major triangular points of Gauss's land-surveying project (namely, Altona Observatory, Brocken, Kleper, and Hoher Hagen). In 2009 an impressive bust of Gauss was set up and inaugurated during a ceremony at the Walhalla memorial near Regens-

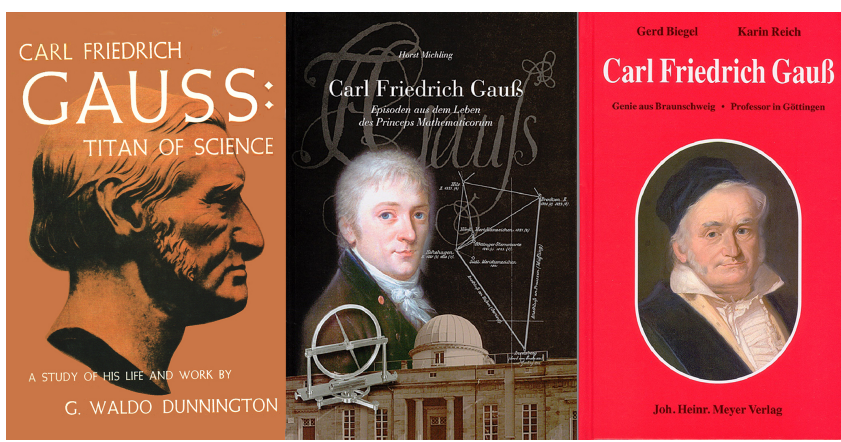

Figure 4. Some of the biographies of Carl Friedrich Gauss published by members of the Gauss Society. From left: Dunnington (1955), Michling (1976), and Biegel and Reich (2005).

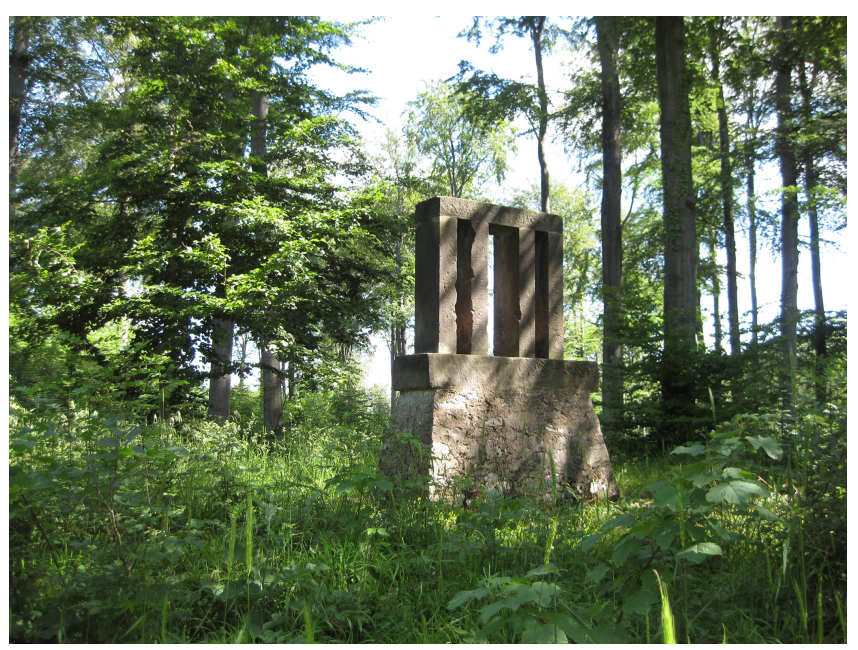

Figure 5. The "Südliches Meridianzeichen", or the southern meridian mark, which is owned by the Gauss Society and is officially listed as a historic monument (photograph by the author).

burg, which is the German hall of fame. In 2012 the Gauss Society celebrated its 50th anniversary in the facilities of the reconstructed Göttingen Astronomical Observatory, which is now called the "Historic Observatory", and - after 190 years or so - is no longer used as an astronomical observatory. The Gauss Society has members mainly in German-speaking European countries (Germany, Austria, and Switzerland), but also in some other countries, particularly in the United States where most of the descendants from Gauss's second marriage (namely his sons Eugen and Wilhelm) live, whereas most of the descendants from his first marriage (his son Joseph) still live in Germany.

The Gauss Society owns a private archive, a collection of books about Gauss and his fields of work, and a collection of items related to Gauss and his family, some of which were donated by his descendants. It also owns a piece of land on a hill near Friedland, $12 \mathrm{~km}$ south of the Göttingen Astronomical Observatory, where Gauss, in 1820, erected 
the "Südliches Meridianzeichen", or the southern meridian mark, which, until about 1930, served to properly align the Reichenbach meridian circle to the south. This usually took place during the daytime when sunlight was shining through the slits of the monument as their distances were built in accordance with the angular distance of the vertical wires of the telescope (Fig. 5). 


\section{Appendix A}

The following is a selection of books about Gauss, in chronological order, which is recommended for further reading.

For an overview of Gauss' works, see Reich (2002) as quoting Gauss himself would be far too numerous a list. Popular books and novels which contain a lot of historical errors are not listed. In the case of multiple or more recent editions, only the first edition is cited.

Sartorius von Waltershausen, W.: Gauß zum Gedächtnis, Verlag S. Hirzel, Leipzig, 108 pp., 1856.

Winnecke, F. A. T.: Gauss, Ein Umriss seines Lebens und Wirkens, Fr. Vieweg und Sohn, Braunschweig, 34 pp., 1877. Hänselmann, L.: Carl Friedrich Gauß, Zwölf Kapitel aus seinem Leben, Duncker \& Humblot, Leipzig, 106 pp., 1878. Bieberbach, L.: Carl Friedrich Gauß, ein deutsches Gelehrtenleben, Keil Verlag, Berlin, 179 pp., 1938.

Dunnington, G. W.: Carl Friedrich Gauss: Titan of science, Exposition Press, New York, 479 pp., 1955.

Roloff, E. A.: Carl Friedrich Gauss, Verlag A. Fromm, Osnabrück, 80 pp., 1941.

Worbs, E.: Carl Friedrich Gauss - Ein Lebensbild, Verlag Koehler \& Amelung, Leipzig, 235 pp., 1955.

Wußing, H.: Carl Friedrich Gauß, B.G. Teubner Verlag, Leipzig, 92 pp., 1974.

Michling, H.: Carl Friedrich Gauß, Episoden aus dem Leben etc., Verlag Göttinger Tageblatt, Göttingen, 141 pp., 1976.

Reich, K.: Carl Friedrich Gauß 1777/1977, Verlag Moos \& Partner, München, 128 pp., 1977.

Küssner, M.: Carl-Friedrich Gauß und seine Welt der Bücher, Musterschmidt Verlag, Göttingen, 184 pp., 1979.

Bühler, W. K.: Gauss. A Biographical Study, SpringerVerlag, Berlin, Heidelberg, New York, 208 pp., 1981.

Biermann, K.-R.: Carl Friedrich Gauß, der Fürst der Mathematiker etc., Urania Verlag, Berlin, 251 pp., 1990.

Reich, K.: Gauss' Werke in Kurzfassung, Dr. Erwin Rauner Verlag, Augsburg, 196 pp., 2002.

Tent, M. B. W.: Carl Friedrich Gauss, The Prince of Mathematics, A.K. Peters, Ltd., Wellesley, MA, 245 pp., 2005.

Biegel, G., and Reich, K.: Carl Friedrich Gauss. Genie aus Braunschweig etc., Joh. Heinr. Meyer Verlag, Braunschweig, 216 pp., 2005.

Mania, H.: Gauß, Eine Biographie, Rowohlt Verlag, Reinbek, 367 pp., 2008.

West, K.: Profiles in Mathematics: Carl Friedrich Gauss, Morgan Reynolds, Greensboro, NC, 112 pp., 2009. 
Competing interests. The author declares that there is no conflict of interest.

Review statement. This paper was edited by Kristian Schlegel and reviewed by Hans Volkert and one anonymous referee.

\section{References}

Biegel, G., and Reich, K.: Carl Friedrich Gauss. Genie aus Braunschweig etc., Joh. Heinr. Meyer Verlag, Braunschweig, 2005.

Dunnington, G. W.: Carl Friedrich Gauss: Titan of science, Exposition Press, New York, 1955.

Gamauf, G.: Erinnerungen aus Lichtenbergs Vorlesungen über Astronomie, Geistingersche Buchhandlung, Wien/Triest, p. 206, 1814.

Hermanowski, G.: Nikolaus Kopernikus Zwischen Mittelalter und Neuzeit, Styria Reprint, Styria, Graz, 284 pp., 193-194 (Copernicus' original handwriting is reproduced on page 193), 1996.

Michling, H.: Carl Friedrich Gauß, Episoden aus dem Leben etc., Verlag Göttinger Tageblatt, Göttingen, 1976.

Reich, K.: Gauss' Werke in Kurzfassung, Dr. Erwin Rauner Verlag, Augsburg, 2002. 